\title{
Mitral valve repair with the new semirigid partial Colvin-Galloway Future annuloplasty band
}

\author{
Ruediger Lange, $M D,{ }^{a}, *$ Thomas Guenther, MD, ${ }^{a}, *$ Birgit Kiefer, MD, ${ }^{a}$ Christian Noebauer, MD, ${ }^{a}$ Wolfgang Goetz, MD, \\ Raymonde Busch, MD, ${ }^{c}$ Peter Tassani-Prell, MD, ${ }^{\mathrm{b}}$ Bernhard Voss, MD, and Robert Bauernschmitt, MD ${ }^{\mathrm{a}}$
}

Supplemental material is available online.
From the Departments of Cardiovascular Surgery $^{\mathrm{a}}$ and Anesthesiology, ${ }^{\mathrm{b}}$ German Heart Center Munich, Clinic at the Technical University, Munich, Germany; and Institute of Medical Statistics and Epidemiology, ${ }^{\mathrm{c}}$ Technical University, Munich, Germany.

R. Lange reports lecture fees from Edwards, Medtronic, and Sorin, R. Bauernschmitt reports consulting fees from Sorin.

* These authors contributed equally to this work and are equal first authors.

Received for publication July 6, 2007; revisions received Nov 4, 2007; accepted for publication Nov 26, 2007.

Address for reprints: Thomas Guenther, MD, Klinik für Herz-und Gefäßchirurgie, Deutsches Herzzentrum, Klinik an der Technischen Universität München, Lazarettstraße 36, D-80636 München (E-mail: Guenther@dhm.mhn.de).

J Thorac Cardiovasc Surg 2008;135:108793

\section{$0022-5223 / \$ 34.00$}

Copyright (C) 2008 by The American Association for Thoracic Surgery

doi:10.1016/j.jtcvs.2007.11.037
Objective: Various devices have been proposed for ring stabilization in patients with mitral valve disease. This study reports the intermediate-term results of mitral valve repair with a new semirigid partial annuloplasty ring in a large series of patients.

Methods: A total of 437 consecutive patients were analyzed who underwent mitral valve reconstruction with annuloplasty using the Colvin-Galloway Future band at the German Heart Center in Munich between 2001 and 2005. A total of 237 patients (54.2\%) underwent isolated mitral valve repair, and 200 patients (45.8\%) underwent a combined procedure. The follow-up is $97 \%$ complete (mean follow-up of 405 survivors $2.1 \pm 1.1$ years).

Results: Overall 30-day mortality was $2.7 \%$. Twenty patients (4.6\%) died later after an average of $1.1 \pm 1.1$ years. Actuarial survival at 4 years after isolated mitral valve reconstruction and combined procedures was $91 \% \pm 4 \%$ and $87 \% \pm 2.5 \%$, respectively $(P<.001)$. Twelve patients $(2.7 \%)$ required a mitral valve reoperation after an average of $4.5 \pm 4.3$ months. Five of these reoperations were required for band dehiscence, and 1 reoperation was required for band fracture. Freedom from reoperation at 4 years was $97 \% \pm 0.9 \%$. At the latest follow-up, $93.5 \%$ of the patients showed trivial or mild mitral valve regurgitation, and $86.4 \%$ of the patients showed New York Heart Association functional class I or II.

Conclusion: Mitral valve annuloplasty with the Colvin-Galloway Future band can be performed with a low early and late mortality and an excellent functional outcome. The low incidence of reoperation demonstrates that the Colvin-Galloway Future band is a safe and effective device. The importance of secure anchoring of the device in the mitral annulus has to be emphasized to prevent band dehiscence.

$\mathrm{M}$ itral valve (MV) reconstruction is the treatment of choice for the majority of patients with MV disease. Because of the pioneering work of Alain Carpentier, reconstructive MV surgery is now standardized with documented excellent long-term results. ${ }^{1-4} \mathrm{MV}$ prosthetic ring annuloplasty is well established and has contributed significantly to the excellent long-term outcome. ${ }^{5}$ In 1969, Carpentier $^{1}$ stated that "the ring restores the normal geometry of the mitral annulus, decreases tension on suture lines, increases the leaflet coaptation, and prevents annular dilation." 1 Although the ring prosthesis as an adjunct to MV repair is generally accepted, there has been an ongoing discussion about the ideal device. Today, complete rigid, flexible, semirigid, and partial devices are in use. ${ }^{4,6-8}$ None of these annuloplasty devices fulfill all the requirements for an optimal MV function, such as preservation of the physiologic dynamics of the MV annulus, restoration of an anterior-posterior ratio of 3:4, and preservation of the 3-dimensional annular saddle-shape. ${ }^{7}$ The Colvin-Galloway (CG) Future annuloplasty band is a new semirigid partial annuloplasty ring first introduced in October of 2001 by Medtronic (Medtronic Inc, Minneapolis, Minn). The present study reports for the first time on the intermediate-term results 


\author{
Abbreviations and Acronyms \\ $\mathrm{AF}=$ atrial fibrillation \\ $\mathrm{CABG}=$ coronary artery bypass grafting \\ $\mathrm{CG}=$ Colvin-Galloway \\ $\mathrm{LV} \quad=$ left ventricular \\ $\mathrm{MV}=$ mitral valve \\ NYHA $=$ New York Heart Association \\ SAM $=$ systolic anterior movement
}

of MV repair with this new device in a large series of patients with a complete follow-up, focusing on the quality of the repair, incidence of reoperation, symptomatic improvement, and functional outcome.

\section{Materials and Methods}

A total of 437 patients aged 18 years or more underwent repair for mitral insufficiency with the CG Future annuloplasty band from December of 2001 to December of 2005 at the German Heart Center Munich. During the same time period, a Carpentier Physio ring (Carpentier-Edwards Physio annuloplasty ring; Edwards Lifesciences LLC, Irvine, Calif) was implanted in 42 patients at special surgeons' preference and MV replacement was performed in 142 patients. These patients were not included in the study. Patients living outside of Europe were excluded from the study because of the inherent difficulty of accurate follow-up. A total of 271 patients $(62 \%)$ were men, and the average age at operation was $63.7 \pm 13.3$ years (range 18-87 years). Preoperative clinical and hemodynamic data are summarized in Table 1. Clinical symptoms, hemodynamic data, and functional outcome were obtained from medical records, patients' follow-up visits, mailed questionnaires, telephone interviews with the patient or family members, and communications from the referring physicians. A total of 373 of 405 patients (92\%) had an echocardiographic assessment at a mean of $1.8 \pm$ 1.1 years after the operation. Echocardiographic examinations were performed by a single investigator with a Siemens Sequoia Acuson System using a 2.5-MHz imaging transducer and included M-mode, continuous-wave 2-dimensional, pulsed-wave Doppler, and color Doppler analyses. The severity of regurgitation was clas- sified as none/trivial (0), mild (I), moderate (II), and severe (III) and was assessed in a semiquantitative manner by means of color Doppler flow mapping. For detection of regurgitation, a color flow Doppler was used with a Nyquist limit (aliasing velocity of $50-60 \mathrm{~cm} / \mathrm{sec}$ ) and a color gain that just eliminated random color speckle from nonmoving areas. The vena contracta was measured in the parasternal long-axis view as the narrowest portion of the jet that occurred at the orifice. The color flow sector was as narrow as possible with the least depth to maximize lateral and temporal resolution.

All evaluations were carried out according to standard techniques recommended by the American Society of Echocardiography. In 356 patients $(81.5 \%)$, the preoperative New York Heart Association (NYHA) functional class was assessed retrospectively: Thirteen patients $(3.7 \%)$ demonstrated NYHA class I, 66 patients (18.5\%) demonstrated NYHA class II, 222 patients $(62.4 \%)$ demonstrated NYHA class III, and 55 patients (15.4\%) demonstrated NYHA class IV. Twenty-six patients $(6 \%)$ had a history of preoperative myocardial infarction at an average of $5.1 \pm 6.6$ years (median 1.9 years) before the operation. A total of 283 patients $(64.8 \%)$ presented with sinus rhythm, 132 patients $(30.2 \%)$ presented with atrial fibrillation (AF), 1 patient presented with complete atrioventricular block, and 21 patients $(4.8 \%)$ had undergone a previous pacemaker implantation. Twenty-one patients $(4.8 \%)$ had previously undergone another cardiac operation.

Etiologic diagnosis was based on medical history and intraoperative and histologic findings. The cause was myxomatous degeneration in 287 patients $(65.7 \%)$, ischemic in 85 patients $(19.5 \%)$, infectious in 31 patients $(7.1 \%)$, congenital in 9 patients $(2.1 \%)$, and rheumatic in 6 patients (1.4\%). Eight patients $(1.8 \%)$ presented with Barlow disease, and 11 patients $(2.5 \%)$ showed other abnormalities. Patients classified as having Barlow disease were usually younger and presented with a larger MV annulus with excess tissue of both mitral leaflets.

\section{Operative Data}

Thirteen patients underwent operation on an emergent basis. An emergent operation was defined as being required within 24 hours after diagnosis. Fifteen patients required an urgent operation, usually with 48 to 72 hours after diagnosis. A total of 237 patients (54.2\%) underwent isolated MV repair; 131 of these patients $(55.3 \%)$ underwent operation through a minimal invasive right anterolateral incision. A total of 200 patients (45.8\%) underwent

TABLE 1. Preoperative patient characteristics

\begin{tabular}{|c|c|c|c|c|}
\hline Variable & All patients & Isolated MV repair & Combined procedures & $P$ value \\
\hline No. of patients & 437 & 237 & 200 & \\
\hline Age (y) Mean \pm SD & $63.7 \pm 13.3$ & $60.8 \pm 13.2$ & $67.3 \pm 12.5$ & $<.001$ \\
\hline Male sex n (\%) & $271(62)$ & $156(66)$ & $115(57.5)$ & .074 \\
\hline Non-sinus rhythm n (\%) & $154(35.2)$ & $74(31.2)$ & $80(40)$ & .056 \\
\hline Preoperative pacemaker n (\%) & $21(4.8)$ & $4(1.7)$ & $17(8.5)$ & .002 \\
\hline NYHA functional class $\geq$ III $n(\%)$ & $268(61)$ & $129(54)$ & $139(69.5)$ & $<.001$ \\
\hline LVEF (angiography) (\%) Mean \pm SD & $57.9 \pm 15.3$ & $62.4 \pm 11.7$ & $52.6 \pm 17.2$ & $<.001$ \\
\hline Previous myocardial infarction $\mathrm{n}(\%)$ & $26(6)$ & $4(2)$ & $22(11)$ & $<.001$ \\
\hline Previous cardiac operation $\mathrm{n}(\%)$ & $21(5)$ & $5(2)$ & $16(8)$ & .004 \\
\hline Previous MV surgery n (\%) & $6(1)$ & $3(1)$ & $3(1.5)$ & .834 \\
\hline
\end{tabular}

$M V$, Mitral valve; $N Y H A$, New York Heart Association; $L V E F$, left ventricular ejection fraction; $S D$, standard deviation. 
MV repair with a concomitant cardiac procedure. Concomitant procedures included coronary artery bypass grafting $(\mathrm{CABG})(\mathrm{n}=79)$, tricuspid valve surgery $(n=48)$, or aortic valve surgery $(n=36)$. Twenty-five patients underwent MV repair in combination with $\mathrm{CABG}$ and tricuspid or aortic valve surgery. Other associated procedures in 12 patients included left ventricular (LV) aneurysm resection, aortic aneurysm resection, left atrial myxoma resection, and atrial septal defect closure. Twenty-nine patients with preoperative persistent AF underwent a modified maze procedure.

\section{Operative Technique}

All operations were performed on cardiopulmonary bypass under systemic hypothermia $\left(26^{\circ} \mathrm{C}-32^{\circ} \mathrm{C}\right)$. Myocardial protection was achieved using cold $\left(4^{\circ} \mathrm{C}\right)$ crystalloid antegrade cardioplegia (Bretschneider solution) or warm-blood cardioplegia. The MV was exposed through a left atrial or right atrial transseptal approach. Segmental valve analysis was performed as described by Carpentier and colleagues. ${ }^{4}$ Sizing was primarily based on the length of the anterior leaflet. Thus, band size was chosen so that the sizer was not totally covered by the anterior leaflet to leave sufficient space for the posterior leaflet to allow for optimal coaptation. In addition, the intertrigonal distance serves as an additive dimension to find an optimal correlation between the height and the width of the anterior leaflet. The majority of patients $(82.2 \%)$ received a Future band size 28 to 32 . The size of the Future band and the number of patients were as follows (size 26 [ $=4$ ], size 28 [ $=126]$, size 30 [ $=112]$, size $32[n=121]$, size 34 [ $=67]$, and size $36[n=7]$. Different repair techniques were applied during the study period (Table 2). All patients were discharged with a regimen of phenprocoumon (Coumadin) for the first 3 months postoperatively. After 3 months, anticoagulant therapy was continued only in patients with chronic and paroxysmal AF.

\section{Follow-up}

Complete follow-up was achieved in 97\%, yielding a cumulative total of 858 patient-years. The follow-up was closed on December 31,2006 . As of January of 2007, 405 patients are alive (mean follow-up $2.1 \pm 1.1$ years, median 1.3 years). Postoperative complications were analyzed according to the "Guidelines for Reporting Morbidity and Mortality after Cardiac Valvular Operations" approved by the Society of Thoracic Surgeons.

\section{TABLE 2. Mitral valve repair techniques}

\begin{tabular}{lrr}
\hline \multicolumn{1}{c}{ Surgical technique } & Patients \\
& $(\mathbf{n})$ & $(\%)$ \\
\hline Isolated ring annuloplasty & 93 & 21.3 \\
PML segmental resection & 88 & 20.1 \\
PML segmental resection + sliding/folding plasty & 63 & 14.4 \\
Chordal replacement with PTFE sutures & 65 & 14.9 \\
Edge-to-edge Alfieri technique & 42 & 9.6 \\
Dreyfus technique & 10 & 2.3 \\
Whooler-type suture & 5 & 1.1 \\
Chordal shortening & 2 & 0.5 \\
Combined procedures & 69 & 15.8 \\
Total & 437 & 100 \\
\hline
\end{tabular}

PML, Posterior mitral leaflet; PTFE, polytetrafluoroethylene.

\section{Statistical Analysis}

Statistical analysis was performed with the Statistical Package for Social Science release 14 (SPSS Inc, Chicago, Ill). Continuous variables are reported as mean \pm 1 standard deviation in the tables and text, and categoric variables are reported as percentages. The chi-square test (for categoric variables) and Mann-Whitney test (for continuous variables) were used to determine statistical differences. The Kaplan-Meier method was used to estimate the late and event-free survival probabilities. Survival estimates are reported as the mean \pm 1 standard error. The log-rank test was used to ascertain differences between groups.

\section{Results}

The mean cardiopulmonary bypass time was $107 \pm 27$ minutes for isolated MV repair and $138 \pm 49$ minutes for combined procedures $(P<.001)$. The mean aortic crossclamping time for isolated $\mathrm{MV}$ repair and combined procedures was $78 \pm 22$ minutes and $96 \pm 27$ minutes, respectively $(P<.001)$. Fourteen patients $(3.2 \%)$ with a combined procedure required intraaortic balloon pump assistance postoperatively. The mean length of hospital stay after solated and combined MV repair was $9 \pm 3$ days and $12 \pm 7$ days, respectively $(P<.001)$

\section{Mortality}

The overall 30-day mortality was $2.7 \%(n=12 / 437)$. None of the 237 patients who underwent isolated MV repair died within 30 days postoperatively. The 30-day mortality was $7.6 \%(6 / 79)$ for $\mathrm{MV}$ reconstruction and CABG, 6.3\% (3/ 48) for concomitant tricuspid valve surgery, $2.8 \%(1 / 36)$ for concomitant aortic valve replacement, and $15.4 \%(2 / 13)$ for MV reconstruction with concomitant CABG and tricuspid/aortic valve surgery. Overall 30-day mortality was $1.96 \%$ (8/409) in electively performed operations, $6.7 \%$ (1/ $15)$ in urgent operations, and $23.1 \%(3 / 13)$ in emergent operations. Twenty patients $(4.6 \%)$ died late after an average of $1.1 \pm 1.1$ years. The cause of death was assessed retrospectively in 20 of 32 patients $(63 \%)$. Seven patients $(35 \%)$ died of a cardiac-related cause, and 13 patients died of a noncardiac-related cause. The actuarial survival probability at 4 years was $89.9 \% \pm 2.2 \%$ for all patients, $91 \% \pm 4 \%$ for patients who underwent isolated MV repair, and $87 \% \pm$ $2.5 \%$ for patients who underwent a combined procedure $(P<.001)$ (Figure E1). The 4-year actuarial survival of patients with degenerative and ischemic MV disease was $96 \% \pm 2 \%$ and $81.3 \% \pm 6 \%$, respectively $(P<.001)$.

\section{Reoperation}

Twelve patients $(2.7 \%)$ required an MV-related reoperation $4.5 \pm 4.3$ months after the initial operation (Table 3 ); 3 of those were performed at another institution: The indication for reoperation was recurrent mitral regurgitation caused by CG Future band dehiscence $(\mathrm{n}=5)$, chordal rupture $(\mathrm{n}=$ $1)$, leaflet suture dehiscence $(n=2)$, progression of ischemic 
TABLE 3. Causes of mitral valve reconstruction failure

\begin{tabular}{llc}
\hline Patient & \multicolumn{1}{c}{ Failure cause } & $\begin{array}{c}\text { Time delay to } \\
\text { reoperation (mo) }\end{array}$ \\
\hline 1 & CG Future band dehiscence (P1, P2, P3) & 6 \\
2 & CG Future band dehiscence (P2) & 6 \\
3 & CG Future band dehiscence (A3, P3) & 1 \\
4 & CG Future band dehiscence (P2) & 4,6 \\
5 & CG Future band dehiscence (A1, P1) + & 2,6 \\
& $\quad$ Leaflet suture dehiscence \\
6 & Leaflet suture dehiscence & 0,7 \\
7 & Leaflet suture dehiscence & 44 \\
8 & Ischemic cardiomyopathy with progressive & 10 \\
& $\quad$ LV dilation and recurrent MVR & 12 \\
9 & Chordal rupture and prolapse (A2, A3) & 2.6 \\
10 & MV endocarditis & 3.7 \\
11 & CG Future band fracture & 7 (d) \\
12 & SAM & \\
\hline
\end{tabular}

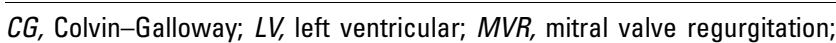
$M V$, mitral valve; $S A M$, systolic anterior movement.

cardiomyopathy $(\mathrm{n}=1)$, CG Future band fracture $(\mathrm{n}=1)$, endocarditis $(\mathrm{n}=1)$, and persistent systolic anterior movement (SAM) $(\mathrm{n}=1)$. In 10 of these cases, the valve was replaced with a biologic $(n=4)$ or mechanical $(n=6)$ prosthesis, and in 2 of these cases, a repeat MV reconstruction was performed. Other reoperations included aortic valve replacement $(n=1)$, tricuspid valve replacement $(n=1)$, and CABG $(n=1)$. Overall freedom from MV-related reoperation at 4 years was $97 \% \pm 1.2 \%$ for isolated MV repair and $97 \% \pm 1.3 \%$ for combined procedures $(P>.05)$ (Figure E2). The reoperation rate was not different for patients who underwent isolated MV repair through a median sternotomy or minimally invasive approach. SAM was diagnosed by intraoperative transesophageal echocardiography in 10 patients. Two patients underwent immediate operative revision (triangular resection of prolapsing A2). Eight patients were treated medically, and 1 of these patients required a reoperation because of persistent SAM 1 week after the initial operation.

\section{Thromboembolism}

Thromboembolic complications, such as stroke $(n=4)$, transient ischemic attack $(\mathrm{n}=1)$, pulmonary embolism $(\mathrm{n}=1)$, central retinal artery occlusion $(n=1)$, and central venous thrombosis $(\mathrm{n}=1)$, occurred in 8 patients $1.3 \pm 1.1$ years (median 0.7 years) after the initial operation. The overall freedom from thromboembolism at 4 years after MV repair was $96 \% \pm 1.6 \%$.

\section{Follow-up Status}

At the latest follow-up, 405 patients were alive. Preoperatively, $67.8 \%$ of the patients showed NYHA functional class III $(60.2 \%)$ and IV (7.6\%). At follow-up, the majority of the patients showed a significant functional improvement. 86.4\% of the patients showed NYHA functional class I and II. A total of 296 of 405 patients $(73.1 \%)$ presented with sinus rhythm, 97 patients presented (24\%) with AF/flutter, 4 patients presented with other rhythm disturbances, and 8 patients were pacemaker dependent. A total of 124 of 132 patients who had presented with $\mathrm{AF}$ at hospital admission are alive. At follow-up, 40 of these patients (32.2\%) presented with sinus rhythm, 80 patients $(64.5 \%)$ were still in $\mathrm{AF}, 3$ patients showed other heart rhythm disturbances, and 1 patient had required a pacemaker implantation. Seven patients experienced a major nonfatal bleeding complication $1.4 \pm 1.2$ years (median 1.1 year) after the initial operation. Four of the 7 patients were taking phenprocoumon. Freedom from bleeding complications after 4 years was $93 \% \pm 4.4 \%$. At the latest follow-up, 124 of 405 survivors (30.6\%) were taking phenprocoumon. Echocardiographic examination, including the preoperative results of the 12 patients who required a reoperation, revealed no or mild mitral regurgitation in 338 of 374 patients $(90.4 \%)$, moderate mitral regurgitation in 19 patients $(5.1 \%)$, and severe mitral regurgitation in 17 patients (4.5\%) (Figures 1 and E3). The mean echocardiographic EF was $55.5 \% \pm 9.5 \%$ (median $60 \%$ ). The results of echocardiographic examinations at different time intervals are summarized in Table E1.

\section{Discussion}

The present study reports for the first time the midterm results of a large series of patients who underwent MV reconstruction with the CG Future band, first introduced by Medtronic in Europe in October of 2001. The CG Future band is a kidneyshaped, partial, low-profile, annuloplasty band containing an elastic stiffener wire made of MP-35N (SPS Technologies, Jenkintown, $\mathrm{Pa}$ ), a nonmagnetic, nickel cobalt-chromium-

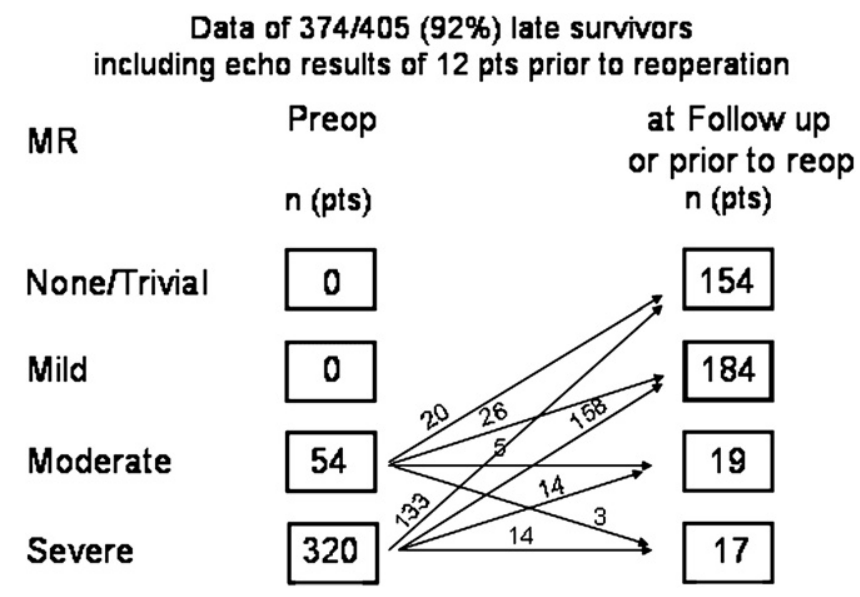

Figure 1. Mitral valve regurgitation (preoperatively and at latest follow-up, including the echocardiography results of 12 patients before reoperation. MR, Mitral regurgitation. 
molybdenum alloy overmolded with silicone and surrounded by a polyester fabric (Medtronic Inc, Minneapolis, Minn). The ratio of the transverse to anterior-posterior internal diameter is approximately 1.75 . The wire core forms eyelets at the trigones to enhance fixation and reduce the anterior ring diameter. Today only a few studies are available reporting results after MV reconstruction with this device. ${ }^{8,9}$ There is common agreement that failure to add an annuloplasty to an MV reconstructive procedure increases the risk of late reoperation. ${ }^{10-12}$ During the past 30 years, various devices for MV annuloplasty have been introduced, ${ }^{4,6,13}$ with major differences in regard to mechanical flexibility, shape, and completeness of the ring. The mitral orifice is a dynamic structure with a complex dynamic interaction between the annulus and the LV outflow tract. ${ }^{14}$ The intertrigonal distance normally expands during diastole, facilitating ventricular filling, and contracts during systole, thereby improving leaflet coaptation. ${ }^{15,16}$ Thus, an ideal annuloplasty device should provide long-term stability of the reconstructive procedure by reducing stress and strain on the leaflets and the chordal structures, and provide a low transvalvular gradient and still preserve all components of a physiologic MV function (eg, restore the anterior-posterior ratio, reduce the posterior ring diameter, maintain the 3-dimensional saddle shape, and allow for a dynamic change in annular diameters during the cardiac cycle). Initially, a complete rigid ring was introduced by Alain Carpentier; however, this initial device was questioned because it alleviates the sphincter-like physiologic dynamics of the mitral annulus and its 3-dimensional saddle shape, making its use potentially responsible for the occurrence of LV outflow tract obstruction ${ }^{17}$ and SAM ${ }^{18}$ as well as the impairment of postoperative LV function. ${ }^{19}$ It was shown that totally flexible complete rings, such as introduced by Duran and Ubago $^{6}$ in 1976, better preserve LV function than complete rigid devices and allow for dynamic annular motion. ${ }^{17,20}$ Therefore, Carpentier later introduced the Physio ring concept,${ }^{4}$ a semirigid complete device that is supposed to provide flexibility to the posterior MV ring, thus allowing annular dynamic motion. However, semirigid complete devices restore the physiologic annular morphology only in 2-dimensions, while the height of the annulus is flattened, the leaflet curvature is diminished, and the saddle shape is abolished. ${ }^{21}$

\section{Rationale for Using Partial Annuloplasty Ring}

The rationale for using a partial ring device is 2 -fold. Gorman and colleagues ${ }^{22}$ described a significant movement of the anterior or fibrotic segment of the MV annulus, although this has been debated by others. ${ }^{23}$ A partial ring like the CG Future band may allow this physiologic intertrigonal annular motion because of its flexibility in the posterior part. By using 3-dimensional transesophageal echocardiography, Sharony and associates ${ }^{8}$ found a $9.6 \%$ reduction in orifice area and a $5.2 \%$ reduction in intertrigonal distance during systole with the CG Future band, which was not observed with the Carpentier-Edwards rigid ring. Consequently, they also noted a significant difference in the mean transvalvular gradients, being $4.0 \pm 0.3 \mathrm{~mm} \mathrm{Hg}$ with the CG Future band and $5.0 \pm 0.3 \mathrm{~mm} \mathrm{Hg}$ with the Carpentier-Edwards rigid ring. ${ }^{8}$ In the present investigation, the mean transvalvular gradient was $2.9 \pm 1.4 \mathrm{~mm} \mathrm{Hg}$ and thus somewhat lower than the $3.55 \pm 1.93 \mathrm{~mm} \mathrm{Hg}$ reported by Carpentier and colleagues ${ }^{4}$ in another study using the Physio ring. A second rationale for using partial devices may be seen in the dynamic interaction between the MV annulus and the LV outflow tract, in that the anterior annulus tilts away from the LV outflow tract and toward the left atrium during systole. ${ }^{17,24,25}$ The preservation of this physiologic deformation could potentially be important in avoiding LV outflow tract obstruction after ring annuloplasty. In an experimental study on sheep, it was shown that these physiologic annular folding dynamics were only preserved with a partial flexible ring (Tailor ring, St Jude Medical, Inc, St. Paul, Minn), but not with a complete flexible ring (Duran ring, Medtronic Inc). ${ }^{26}$ Furthermore, it was shown recently that mitral annulus deformation is closely related to aortic root dynamics in that aortic root reduction during diastole participates in mitral annulus dilatation. ${ }^{16}$ Allowing more cyclic changes in annular motion partial ring devices, such as the CG Future band, may also interfere less with the LV outflow tract. A potential disadvantage of partial rings might be seen in an insufficient reduction of the anterior portion of the mitral annulus. In postmortem studies of hearts from patients with ischemic and dilated cardiomyopathy, Hueb and colleagues ${ }^{27}$ showed that the dilatation of the mitral annulus affects not only the muscular but also the fibrous portion. In an ovine model of ischemic mitral regurgitation, Gorman and colleagues ${ }^{22}$ also demonstrated progressive dilatation of both the anterior and posterior part of the mitral annulus. This potential drawback of partial rings was addressed in the design of the CG Future band by the construction of the eyelets, which are supposed to be anchored in the fibrous trigones, thus also reducing the anterior part of the annulus. The CG Future band is supposed to allow remodeling of the anterior-posterior diameter and dynamic expansion of the intertrigonal distance during the cardiac cycle and may interfere less with the motion between the mitral annulus and the LV outflow tract than completely rigid rings.

\section{Quality of Repair}

In addition to the hemodynamic performance of annuloplasty devices, the stability of the valve reconstruction at long term, expressed by the recurrence of mitral regurgitation, deserves the main focus when choosing a device. In this respect, the incidence of repair failure is similar to that of semirigid and flexible rings. ${ }^{11}$ Few studies have reported functional results after CG Future band implantation. In a study of 40 patients with a mean follow-up of $16.5 \pm 5.7$ months, Fasol and colleagues ${ }^{9}$ found no or $1+$ mitral regurgitation in $91.1 \%$ of 
patients. In the study by Sharony and colleagues, ${ }^{8} 95 \%$ of the patients with the CG Future band were found to have either no or trace mitral insufficiency with no difference to patients with the Carpentier-Edwards Classic ring. In the present series, $90.4 \%$ of patients showed no or mild mitral regurgitation at the latest follow-up after $2.1 \pm 1.1$ years. This compares favorably to functional results after implantation of the Carpentier-Edwards Physio ring. Carpentier and colleagues ${ }^{4}$ reported that $94.7 \%$ of the patients exhibited no, and $5.3 \%$ mild residual mitral regurgitation 12 months after repair. Accola and colleagues ${ }^{28}$ found no-trace-trivial or $1+$ insufficiency in $89.4 \%$ of patients and $2+$ in $10.6 \%$ of patients $3.2 \pm 1.7$ years after the initial operation. Failure of valve reconstruction is rare. In the study by Accola and colleagues, ${ }^{28} 11$ of 492 patients $(2.3 \%)$ required a reoperation because of reconstruction failures 4.3 to 87.7 months after MV repair with the Physio ring. In one case, the ring was dislodged. The freedom from reoperation at 4 years was $81.5 \% \pm 2.1 \%$. According to Carpentier and colleagues, ${ }^{4}$ only 4 of 137 patients (2.9\%) who underwent annuloplasty with a Physio ring had to undergo reoperation. In our study, 12 patients $(2.7 \%)$ required a reoperation $4.5 \pm 4.3$ months after the initial operation. Procedure-related failures, such as CG Future band dislodgment and suture dehiscence, were the main reasons. Dislodgement of the device occurred in 5 of 11 patients, 4 at the posterior ring/commissure and 1 at the anterior commissure. Apparently the forces exerted on the posterior part of the ring are higher than with a complete device, where the radiant traction forces are dissipated over the entire annulus. All of these events occurred in the beginning of our experience with the CG Future band, with only 1 incidence occurring after the year 2003. Thus, we emphasize the importance of exact placement of the annuloplasty sutures deep and precisely into the mitral annulus to ensure secure fixation. One patient presented with CG Future band fracture. The fracture occurred at the midpoint of the CG Future band and led to recurrent annular dilatation. One incidence of a fracture was reported by Hartrumpf and colleagues: ${ }^{29}$ The metal skeleton broke near the posteromedial commissure. To date, in excess of 20,000 CG Future bands have been implanted, and the reported overall incidence of fractures is approximately $0.09 \%$ (communication by the manufacturer: Medtronic Inc, February 6, 2007). Consequently, the specification for the CG Future band wire stiffener material was updated by Medtronic Inc with respect to dimensional tolerances, alloy chemistry, and mechanical properties. In the present study, freedom from MV-related reoperation at 4 years after MV reconstruction was $97 \% \pm 1.2 \%$ with no difference between patients who underwent isolated MV repair or a combined procedure. All reoperations have been performed early within the first year after MV repair. In a series of 1072 patients who underwent isolated MV repair with 4 different annuloplasty techniques, Gillinov and colleagues ${ }^{12}$ report a 10year freedom from reoperation rate of $93 \%$. By using the
Physio ring, Accola and colleagues ${ }^{28}$ found a freedom from reoperation at 4 and 7 years of $81.5 \% \pm 2.1 \%$ and $67.9 \%$ $\pm 4.6 \%$, respectively. With the use of the Carpentier Classic ring in 120 patients, Soyer and colleagues ${ }^{30}$ found freedom from reoperation at 5 years to be $95.2 \%$. Thus, the functional results after repair with the CG Future band are excellent and in line with previous reports using other annuloplasty devices.

\section{Thromboembolism}

Many studies do not describe the anticoagulation regimen or the incidence of AF. In our series, all patients were discharged with a regimen of phenprocoumon for the first 3 months postoperatively. The referring physicians were advised to continue anticoagulation therapy in patients with AF. The freedom from thromboembolism at 4 years after MV repair was $96 \% \pm 1.6 \%$ for all patients, which compares favorably to other studies in which freedom from thromboembolism was found to be $93 \% 5$ years after repair with a Carpentier Classic ring. ${ }^{30}$

\section{Mortality}

In our series, the overall 30 -day mortality was $2.74 \%$, with no death in the isolated MV repair group and 6\% in the combined procedure group. This compares favorably to the results of other studies in which complete or open semirigid, flexible, or rigid annuloplasty rings were used. In a series of $137 \mathrm{pa}-$ tients with isolated MV reconstruction using the Physio ring, Carpentier and colleagues ${ }^{4}$ reported an early mortality of $2 \%$. Gillinov and co-authors ${ }^{12}$ analyzed 1072 patients with isolated MV repair with a Cosgrove-Edwards band or a Carpentier-Edwards Classic ring and reported a hospital mortality of $0.3 \%$. Accola and colleagues ${ }^{28}$ analyzed 492 patients who underwent MV reconstruction with a Physio ring and reported a hospital mortality of $2.1 \%$ for isolated MV reconstruction and $4.9 \%$ for patients with concomitant CABG. The actuarial survival probability at 4 years in the present study was $91 \% \pm 4 \%$ for isolated MV repair and $87 \% \pm 2.5 \%$ for combined procedures. Accola and colleagues ${ }^{28}$ observed an actuarial survival at 4 years of $81.5 \%$ $\pm 2.1 \%$, not differentiating between isolated and combined procedures.

\section{Study Limitations}

Our study is a retrospective study with all of the inherent limitations. In addition, the influence of the competing risk of death has to be considered when the event-free survival from valve-related complications, such as thromboembolism, bleeding, or reoperation, is calculated according to the Kaplan-Meier method, because the probability of reoperation, for example, may be overestimated when the patients who died before the event occurred are censored. 


\section{Conclusions}

Presently, MV reconstruction in patients with isolated MV disease is performed with a low operative mortality (Gillinov and colleagues: ${ }^{12} 0.3 \%$; Carpentier and colleagues: ${ }^{4} 2 \%$; Accola and colleagues: ${ }^{28} 2.1 \%$; German Heart Center: $0 \%$ ). The functional results are excellent. A significant symptomatic improvement can be achieved in more than $95 \%$ of patients, the majority of the patients present with no or mild residual mitral regurgitation, ${ }^{4,8,9}$ and the incidence of reoperation is low (Carpentier and colleagues: ${ }^{4} 2.9 \%$; Accola and colleagues: ${ }^{28} 2.2 \%$; German Heart Center: $2.7 \%$ ). Ring annuloplasty is a key factor in the efficacy of these operations, 4,12 whereas the type of annuloplasty does not seem to have a significant influence, at least in terms of survival and repair durability.

We demonstrated that MV reconstruction using the CG Future band can be performed with a low 30-day and late mortality and an excellent functional outcome. The low incidence of reoperation demonstrates that the CG Future band is a safe and effective device for mitral annuloplasty. The secure fixation of this device, especially in the posterior part of the annulus, is of the utmost importance.

\section{References}

1. Carpentier A. La valvuloplastie reconstitutive. Une nouvelle technique de valvuloplastie mitrale. Presse Med. 1969;77:251-3.

2. Carpentier A. Cardiac valve surgery-the "French correction." J Thorac Cardiovasc Surg. 1983;863:23-37.

3. Deloche A, Jebara VA, Relland JYM, Chauvaud S, Fagiani JN, Perire P, et al. Valve repair with Carpentier techniques. The second decade. J Thorac Cardiovasc Surg. 1990;99:990-1002.

4. Carpentier A, Lessana A, Relland JYM, Belli E, Mihaileanu S, Berrebi AJ, et al. The "Physio-Ring" an advanced concept in mitral valve annuloplasty. Ann Thorac Surg. 1995;60:1177-86.

5. Gillinov AM, Cosgrove DM. Mitral valve repair for degenerative disease. J Heart Valve Dis. 2002;11(Suppl 1):S15-20.

6. Duran CG, Ubago JL. Clinical and hemodynamic performance of a totally flexible prosthetic ring for atrioventricular valve reconstruction. Ann Thorac Surg. 1976;22:458-63.

7. Cosgrove DM, Arcidi JM, Rodriguez L, Stewart WJ, Powell K, Thomas JD. Initial experience with the Cosgrove-Edwards annuloplasty system. Ann Thorac Surg. 1995;60:499-503.

8. Sharony R, Saunders PC, Nayar A, McAleer E, Galloway AC, Delianides J, et al. Semirigid partial annuloplasty band allows dynamic mitral annular motion and minimizes valvular gradients: an echocardiographic study. Ann Thorac Surg. 2004;77:518-22.

9. Fasol R, Meinhart J, Deutsch M, Binder T. Mitral valve repair with the Colvin-Galloway Future band. Ann Thorac Surg. 2004;77:1985-8.

10. Czer LS, Maurer G, Trento A, DeRobertis M, Nessim S, Blanche C, et al. Comparative efficacy of ring and suture annuloplasty for ischemic mitral regurgitation. Circulation. 1992;86(Suppl 2):II46-52.

11. Cohn LH, Couper GS, Aranki SF, Rizzo RJ, Kinchla NM, Collins JJ. Long-term results of mitral valve reconstruction for regurgitation of the myxomatous mitral valve. J Thorac Cardiovasc Surg. 1994;107: 143-51.

12. Gillinov AM, Cosgrove DM, Blackstone EH, Diaz R, Arnold JH, Lytle BW, et al. Durability of mitral valve repair for degenerative disease. J Thorac Cardiovasc Surg. 1998;116:734-43.

13. Carpentier A, Deloche A, Dauptain J, Soyer R, Blondeau P, Piwnica A, et al. A new reconstructive operation for correction of mitral and tricuspid insufficiency. J Thorac Cardiovasc Surg. 1971;61:1-13.

14. Komoda T, Hetzer R, Oellinger J, Siniawski H, Hofmeister J, Hubler M, et al. The relationship between the mitral annulus and left ventricular outflow tract. Asaio J. 1997;43:932-6.

15. Glasson JR, Komeda M, Daughters GT, Niczyporuk MA, Bolger AF, Ingela NB, et al. Three-dimensional regional dynamics of the normal mitral annulus during left ventricular ejection. $J$ Thorac Cardiovasc Surg. 1996;111:574-85.

16. Lansac E, Lim KH, Shomura Y, Gotz WA, Lim HS, Rice NT, et al. Dynamic balance of the aorta mitral junction. $J$ Thorac Cardiovasc Surg. 2002;123:911-8.

17. Van Rijk-Zwikker GL, Mast F, Shipperheyn JJ, Huysmans HA, Bruschke AV. Comparison of rigid and flexible rings for annuloplasty of porcine mitral valve. Circulation. 1990;82(suppl 4):IV58-64.

18. Kreindel MS, Schiavone WA, Lever JM, Cosgrove D. Systolic anterior motion of the mitral valve after Carpentier ring valvuloplasty for mitral valve prolapse. Am J Cardiol. 1986;57:408-12.

19. David TE, Komeda M, Pollick C, Burns RC. Mitral valve annuloplasty: the effect of the type on left ventricular function. Ann Thorac Surg. 1989; 47:524-7.

20. Okada Y, Shomura T, Yamaura Y, Yoshikawa J. Comparison of the Carpentier and Duran prosthetic ring used in mitral reconstruction. Ann Thorac Surg. 1995;59:658-63.

21. Salgo IS, Gorman JH 3rd, Gorman RC, Jackson BM, Bowen FW, Plappert T, et al. Effect of annular shape on leaflet curvature in reducing mitral leaflet stress. Circulation. 2002;106:711-7.

22. Gorman JH III, Gorman RC, Jackson BM, Enomoto Y, St JohnSutton MG, Edmunds LH Jr. Annuloplasty ring selection for chronic ischemic mitral regurgitation: lessons from the ovine model. Ann Thorac Surg. 2003;76:1556-63.

23. McCarthy PM. Does the intertrigonal distance dilate? Never say never. J Thorac Cardiovasc Surg. 2002;124:1078-9.

24. Goetz W, Lansac E, Lim HS, Stevens SA, Weber PA, Duran C. Kinking of the atrioventricular plane during the cardiac cycle. Asian Cardiovasc Thorac Ann. 2006;14:394-8.

25. Komoda T, Hetzer R, Oellinger J, Sinlawski H, Hofmeister J, Hubler M, et al. Mitral annular flexibility. J Card Surg. 1997;12:102-9.

26. Dagum P, Timek T, Green GR, Daughters GT, Liang D, Ingels NB, et al. Three dimensional geometric comparison of partial, and complete flexible mitral annuloplasty rings. J Thorac Cardiovasc Surg. 2001; 122:665-73.

27. Hueb AC, Jatene FB, Moreira LF, Pomerantzeff PM, Kallas E, de Oliveira SA. Ventricular remodelling and mitral valve modifications in dilated cardiomyopathy: new insights from anatomic study. J Thorac Cardiovasc Surg. 2002;124:1216-24.

28. Accola KD, Scott ML, Thompson PA, Palmer GJ, Sand ME, Ebra G. Midterm outcomes using the physio ring in mitral valve reconstruction: experience in 492 patients. Ann Thorac Surg. 2005;79:1276-83.

29. Hartrumpf M, Stock UA, Kuehnel RU, Albes JM. Fracture of ColvinGalloway Future band causing a tear in the anterior mitral leaflet. Ann Thorac Surg. 2006;81:1879-80.

30. Soyer R, Bouchart F, Bessou JP, Tabley A, Mouton-Schleifer D, Redonnet M, et al. Mitral valve reconstruction: long-term results of 120 cases. Cardiovasc Surg. 1996;4:813-9. 


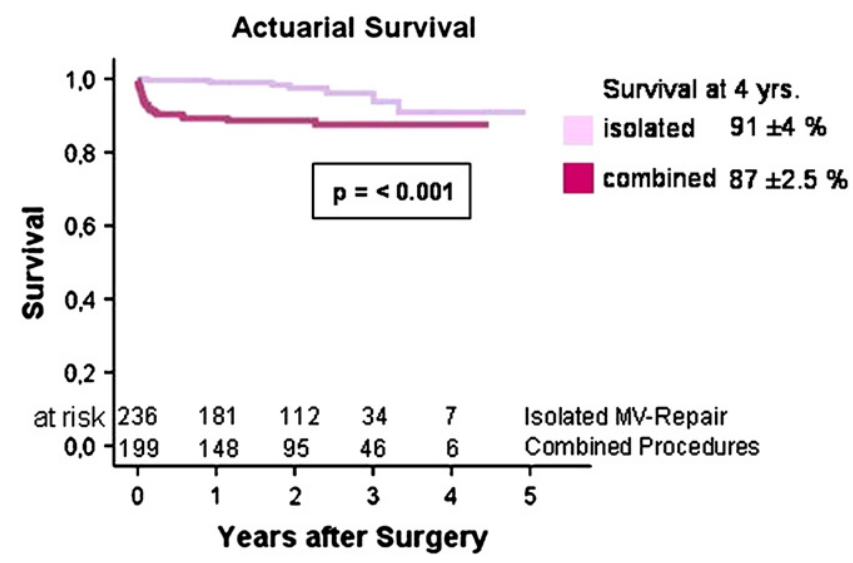

Figure E1. Actuarial survival after MV repair. Kaplan-Meier estimate of survival for patients who underwent isolated MV repair or MV repair with concomitant CABG and/or aortic/tricuspid valve surgery. Survival estimates are reported as the mean \pm 1 standard error. The actuarial survival probability at 4 years was $91 \% \pm 4 \%$ for patients who underwent isolated MV repair and $87 \% \pm 2.5 \%$ for patients who underwent a combined procedure. MV, Mitral valve. 


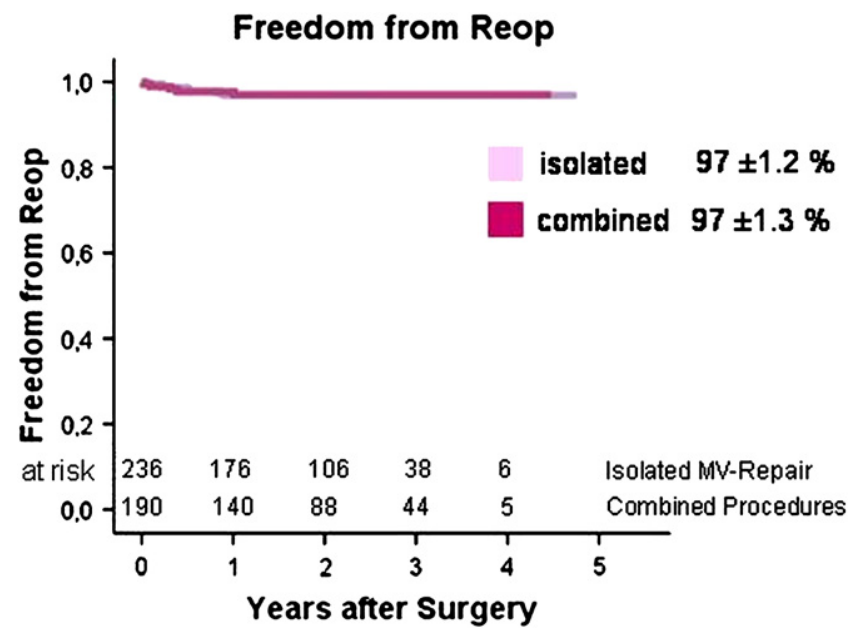

Figure E2. Freedom from MV-related reoperation. Kaplan-Meier estimate of freedom from reoperation for patients who underwent isolated MV repair or MV repair with concomitant CABG and/or aortic/tricuspid valve surgery. Freedom from MV-related reoperation at 4 years was $97 \% \pm 1.2 \%$ for isolated $M V$ repair and $97 \% \pm$ $1.3 \%$ for combined procedures. Estimates of freedom from reoperation are reported as the mean \pm 1 standard error. $M V$, Mitral valve. 


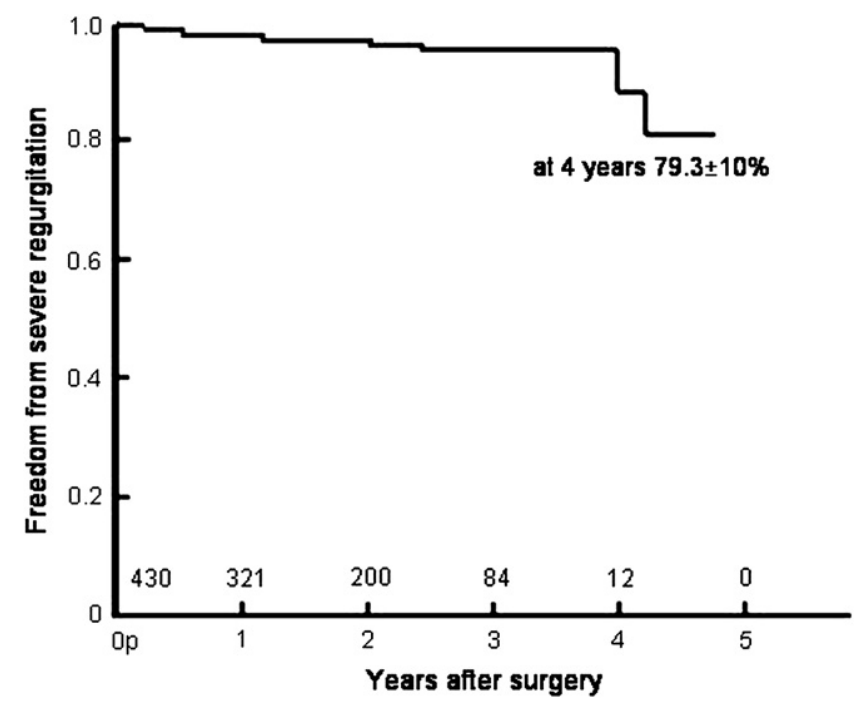

Figure E3. Freedom from severe MVR. Kaplan-Meier estimate of freedom from severe MVR. Freedom from severe MVR 4 years after MV repair was $79.3 \% \pm 10 \%$ (mean \pm 1 standard error). 
TABLE E1. Results of echocardiographic studies at different time intervals ( $\mathbf{n}=\mathbf{3 7 3}$ patients)

\begin{tabular}{|c|c|c|c|c|}
\hline Date of study & $\leq 1 y$ & 1 to $\leq 2 y$ & 2 to $\leq 3 y$ & $\geq 3 y$ \\
\hline \multirow[t]{2}{*}{ Patients (n) } & 100 & 121 & 98 & 54 \\
\hline & Mean $\pm S D$ & Mean $\pm S D$ & Mean $\pm S D$ & Mean \pm SD \\
\hline Septum (mm) & $11.9 \pm 2.0$ & $11.4 \pm 2.1$ & $11.8 \pm 1.5$ & $11.1 \pm 1.7$ \\
\hline Posterior wall (mm) & $11.6 \pm 2.3$ & $11.1 \pm 2.0$ & $11.7 \pm 1.5$ & $10.9 \pm 1.7$ \\
\hline LVEDD (mm) & $52.3 \pm 5.5$ & $51.9 \pm 6.7$ & $51.4 \pm 5.6$ & $52.5 \pm 7.9$ \\
\hline LVESD (mm) & $35.2 \pm 6.0$ & $34.8 \pm 6.5$ & $34.5 \pm 5.3$ & $36.4 \pm 7.7$ \\
\hline LAESD (mm) & $44.5 \pm 6.0$ & $46.8 \pm 8.8$ & $48.3 \pm 10.4$ & $48.8 \pm 9.4$ \\
\hline$\Delta \mathrm{P}(\mathrm{mm} \mathrm{Hg})$ & $2.7 \pm 1.4$ & $2.5 \pm 1.3$ & $2.5 \pm 1.0$ & $2.9 \pm 1.4$ \\
\hline $\mathrm{EF}(\%)$ & $55.8 \pm 10.4$ & $55.2 \pm 9.1$ & $57.0 \pm 7.0$ & $52.6 \pm 11.5$ \\
\hline
\end{tabular}

SD, Standard deviation; $L V E D D$, left ventricular end-diastolic diameter; $L V E S D$, left ventricular end-systolic diameter; $L A E S D$, left atrial end-systolic diameter; $\Delta P$, transvalvular pressure gradient; $E F$, ejection fraction. 